\title{
JingShin Theoretical Physics Symposium in Honor of Professor Ta-You Wu
}


This page is intentionally left blank 


\title{
JingShin Theoretical Physics Symposium in Honor of Professor Ta-You Wu
}

\author{
editors \\ Jong-Ping Hsu \\ University of Massachusetts \\ Leonardo Hsu \\ Carnegie Mellon University
}




\section{Published by}

World Scientific Publishing Co. Pte. Ltd.

P O Box 128, Farrer Road, Singapore 912805

USA office: Suite 1B, 1060 Main Street, River Edge, NJ 07661

UK office: 57 Shelton Street, Covent Garden, London WC2H 9HE

\section{British Library Cataloguing-in-Publication Data}

A catalogue record for this book is available from the British Library.

\section{JINGSHIN THEORETICAL PHYSICS SYMPOSIUM IN HONOR OF PROFESSOR TA-YOU WU}

\section{Copyright (C) 1998 by World Scientific Publishing Co. Pte. Ltd.}

All rights reserved. This book, or parts thereof, may not be reproduced in any form or by any means, electronic or mechanical, including photocopying, recording or any information storage and retrieval system now known or to be invented, without written permission from the Publisher.

For photocopying of material in this volume, please pay a copying fee through the Copyright Clearance Center, Inc., 222 Rosewood Drive, Danvers, MA 01923, USA. In this case permission to photocopy is not required from the publisher.

ISBN 981-02-3372-8

Printed in Singapore by Uto-Print 


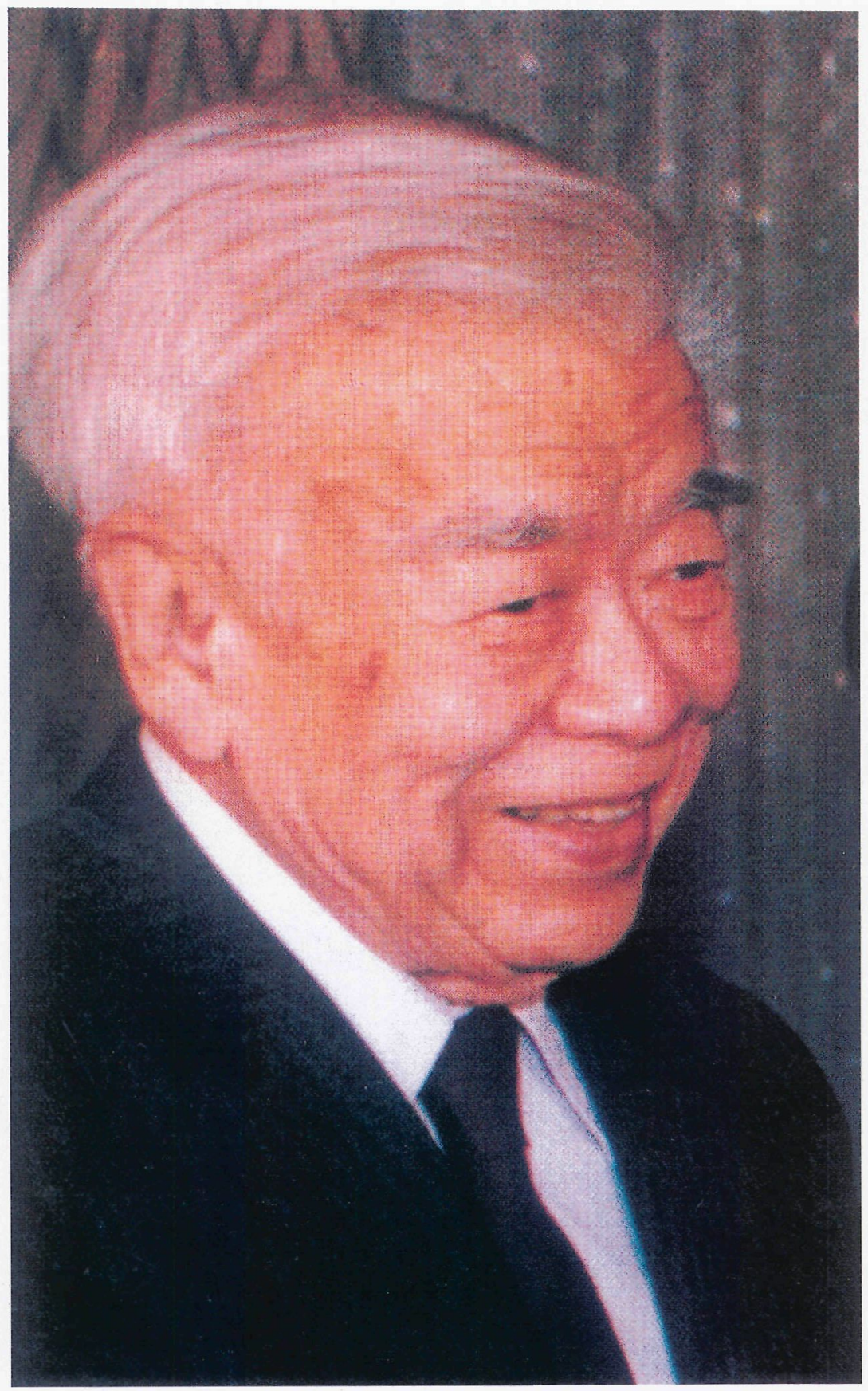


This page is intentionally left blank 


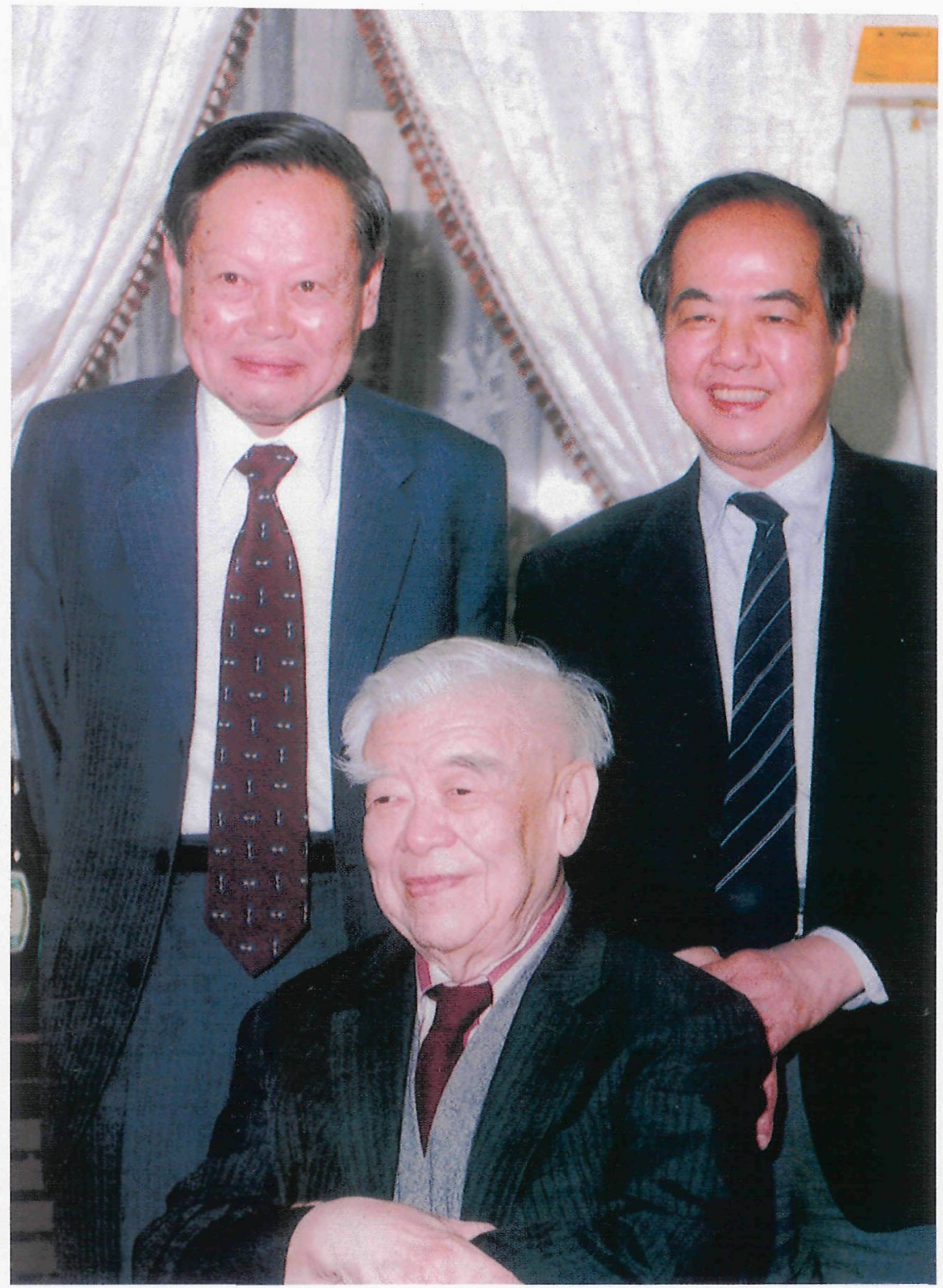

A Precious Moment (May, 1997)

C. N. Yang (left), T. D. Lee (right) and their teacher T. Y. Wu

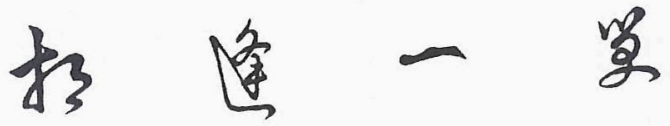


This page is intentionally left blank 


\section{Foreword}

\section{Dr. Ta-You Wu and Academia Sinica}

\section{Yuan-Tseh Lee}

It is indeed our pride and pleasure to witness Dr. Ta-You Wu's healthy sailing into his nineties. An occasion that calls for celebration of his immeasurable achievements as a scientist and of his invaluable contributions to Academia Sinica and to the scientific community in general.

Dr. Wu was born in Canton, China in 1907. He did his undergraduate studies in Nankai University in Tientsin and was graduated from it in 1929. Then he earned his M.S. and Ph.D. degrees in two years (1931-1933) at the University of Michigan, Ann Arbor. U.S.A. After that, he taught as a professor of physics and conducted his research at the National University of Peking. In 1946, he went to the United States, serving first as a visiting professor at the University of Michigan and then spent many years teaching physics at several universities in the US and Canada. He was elected an academician of Academia Sinica in 1948, an unusual honor for a scholar just past forty. In 1956 he returned to Taiwan and taught at the National Taiwan University and devoted most of his time to teaching and research in Taiwan ever since.

Aside from conducting his own research. his enormous innovation and contributions in promoting and upgrading academic research in Taiwan led to his appointment as the President of Academia Sinica in 1983. During his tenure, he set to build a system

Yuan-Tseh Lee is the President of the Academia Sinica, Taiwan. He received the Nobel Prize for Chemistry in 1986 for his contributions to the chemical-reaction dynamics. He developed the crossed molecular beam technique to enable the investigation of larger and more complex molecules. In 1993, he made the momentous decision to return to Taiwan and helped the development of science and technology. This article was written for a special issue of the Chinese Journal of Physics (Dec. 1997) in honor of Dr. Ta-You Wu. 
that could enhance the quality of basic research and that would fit the unique atmosphere of the Academy by prompting the amendment of appointment, evaluation and promotion procedures for research faculties. The revised ordinance was soon approved as well as implemented; his insightful views and staunch determinations to boost research won acclaim and support inside and outside of the Academy.

Dr. Wu also placed great emphasis on expanding the scale of research as well as the body of faculties of the Academy. He continued to execute the Second and the Third "Five-Year Development Program" of the Academy, recruiting many prominent or aspiring scholars to join the Academy; seeking more funds for research facilities and upgrading the level of academic research as a whole. During his tenure as President of Academia Sinica, three new preparatory offices of institutes were established, namely Institute of Astronomy and Astrophysics, Institute of Chinese Literature and Philosophy, and Institute of Taiwan History to further extend the Academy's research body.

One of the most significant contributions Dr. Wu made is his insistent advocating to continue the independence and freedom of basic research, which helped keep Academia Sinica in its unique position. It was also his efforts that laid a more solid foundation for Academia Sinica's development in the later years. His outstanding accomplishments in the fields of physics, academic research, education, and scholarship shall be remembered all the time.

In addition, Dr. Wu is also widely known for his candid heartiness towards life and unyielding frankness towards issues. Remaining true to his heart and standing firm on his principles, his sometimes untimely outspokenness has won recognition and respect from all walks of life. To those who have had the privilege and pleasure of knowing him personally, he must be very special always, a mentor of his own kind.

Let us all wish him health and happiness. 


\section{Preface}

When we learned that Prof. Wu* Ta-You (T. Y. Wu), at the age of 90 , still actively gave lectures on special topics in physics and was revising his seven volumes on theoretical physics, we were awestruck. After nearly forty years, many physicists still have fond memories of discussing problems with Prof. Wu as college students in Taiwan around 1960. At that time, his visits to Taiwan (which was then very backward in science) to give lectures and colloquia on physics were always big and exciting events to students of physics. Recently, an old friend confirmed that many people also appreciated Prof. Wu's help with the making of science and technology policy in Taiwan.

Prof. Wu's life has been characterized by his scholarship and love of physics -- a life of learning, search and research without end. It is no wonder that friends and colleagues organized a symposium in 1978 on the occasion of his retirement from the State University of New York at Buffalo (resulting in the book "The Ta-You Wu Festschrift: Science and Matter") and also one in 1991 when he received an honorary degree at the University of Michigan, Ann Arbor. The National Tsing Hua University (Taiwan) organized a grand birthday party for Prof. Wu in May 1997 in which students, professors and many university presidents from Taiwan and mainland China participated. His former students, Profs. C. N. Yang and T. D. Lee, both Nobel laureates of physics for their joint contribution on the nonconservation of parity, presented talks on "The Introduction of Sciences into China and Development," "Science and Technology in Ancient China" and "The Challenge of Physics Today." In one lecture, Prof. Lee presented his theory of the ancient Chinese jades $\mathrm{Pi}$, Tsung and Xuan $\mathrm{Ji}$ as artistic expressions of astronomical instruments for the determination of the Fixed Point in the sky (circa 2700 B.C.). These talks sparked an exciting discussion concerning the causes for the apparent sudden stagnation of scientific development in China at a time when modern science was developing rapidly in Europe after the renaissance. Professor Wu 
said that he accepted the generally held view that the dominance of Confucianism in Chinese civilization and the examination system for civil service during the last twenty four centuries have shaped both the aim and the nature of the Chinese civilization, and that these were the direct causes for the lack of development of science. However, Prof. Wu believes that a much deeper cause lies in the intense humanistic elements that have formed and become ingrained in Chinese thought from the beginning of the agricultural civilization, about 2000-3000 B.C., long before Confucius' teachings (after 500 B.C.). These intense humanistic elements have lead to a civilization which tends to be "practical" as opposed to "abstract". Thus almost all the well-known inventions and discoveries of the Chinese such as silk, herb medicine, bronze, various mechanical devices, gun powder, paper, printings, etc. are of a technical nature. The Mohtz ( 400 B.C.) has given a complete description of the geometric optics of mirrors, including virtual images, but has taken no interest in the nature of light; it has the principles of lever systems (statics) but has nothing near general dynamics. The Chinese have alchemy and practical metallurgy but not the beginnings of chemistry. The Chinese are weak in religious philosophies. The ancient Book-of-Changes (800 200 B.C.) does not deal with "abstract" concepts.

In September 1997, a two-day symposium in honor of Prof. Wu was held at the University of Massachusetts Dartmouth and these proceedings are the result. In addition, some of his former students and colleagues have contributed papers to a special issue of the Chinese Journal of Physics dedicated to Professor Wu.

Prof. Wu* Ta-You is not only an eminent physicist with an encyclopedic knowledge, but also a motivational teacher and a guiding force for the development of policy relating to science and technology in Taiwan. As a young student, Wu was inspired by Prof. Yao* Yu-Tai, whose course on modern physics sparked an interest that lasted for a long and productive career. Even at the age of 90, he remains active, publishing papers and lecturing on physics. Indeed, it is a pleasure to honor him and to reminisce on his contributions. 
Among his achievements, Wu has published 14 books and more than 120 papers covering subjects from atomic and molecular physics to plasmas and gases to atmospheric physics to relativity theory. He has done pioneering work on the energy levels of transuranium elements, the doubly-excited states and autoionization of $\mathrm{He}$ atoms, a kinematic approach to transformations for accelerated frames, and the time arrow and concept of irreversibility introduced using a general 'probability Ansatz.' It appears that Wu's original idea of a kinematic approach to finding an accelerated transformation has a potential that has not yet been fully explored.

Prof. Wu is grateful to have had the opportunity to educate a group of extremely talented students and in particular, to have discovered T. D. Lee's remarkable ability. Although creative talent is no doubt a product of nature, it must also be nurtured and developed. Prof. $\mathrm{Wu}$ has played this crucial role for an entire generation of physicists in China and has won great respect from former students such as C. N. Yang, T. D. Lee, K. Huang, S. T. Ma and countless others. His dedication to teaching and research will always be remembered. This commemorative volume is our modest contribution in appreciation of Prof. Wu and his love of physics.

Both the symposium and the preparation of this book have involved the generous help of many friends and colleagues who presented talks and contributed papers. We also owe a large debt of gratitude to the Jing Shin Research Fund, the UMassD Physics Department and the Potz Science Fund for financial support, and to Prof. K. K. Phua for the publication.

Jong-Ping Hsu

Leonardo $\mathrm{Hsu}$

Note. We attach an asterisk to a Chinese surname when it appears in front of the given name, e.g., $\mathrm{Wu}^{*} \mathrm{Ta}-\mathrm{You}$. This is the customary naming convention in China. 
xiv

\section{Note Added by Editors}

Teaching has been an essential part of Prof. Wu's life. In recent years, an increasing amount of work has been focused on innovative teaching methods in physics - partially in response to the decline in enrollments in physics programs over the past decade in the U.S. One successful example is described by Prof. Charles Chiu in his paper. As a result of this work, he was selected as the twelfth annual Friar Fellow by the University of Texas at Austin for his contribution to innovative teaching methods of physics and his dedication to pursuing excellence in higher education. He has also been selected as a member of the Academy of Distinguished Teachers at the University of Texas at Austin. 


\section{Contents}

Foreword - Dr. Ta-You Wu and Academia Sinica $\quad$ ix Yuan-Tseh Lee

Preface

Jong-Ping Hsu and Leonardo Hsu

The Scientific Research and Teaching of Ta-You Wu

Jong-Ping Hsu

Scientific Publications of Ta-You Wu (Selected)

Reminiscences of My Ann Arbor Days Ta-You Wu

Comments after Professor Wu's Talk Chen Ning Yang

Paragon of Scholars and Great Master of Physics Zhou* Guangzhao

The Ta-You Wu Lectures at the University of Michigan Alfred C. T. Wu

\section{Innovative Ideas in Physics}

Einstein's Impact on Theoretical Physics

Chen Ning Yang

Innovation in Physics (with Note Added Forty Years Later)

Freeman J. Dyson

\section{Atomic and Molecular Physics}

Vibration of the Carbon- 60 Molecule

Tsu-Teh Chou and Chen Ning Yang

Classification and Quantum Number of Doubly-Excited ${ }^{1}$ Po Resonances

of Helium

Kwong T. Chung

\section{Condensed Matter and Statistical Physics}

Effects of Heavy and Light Hole Mixing in Quantum Well Physics

Kun Huang

Knot Theory and Statistical Mechanics 
Mean-Field and Perturbation Theory of Vortex-like Composite Fermions Yong-Shi Wu and Yue Yu

\section{Quantum Mechanics}

Angular Momentum, Quaternion, Octonion, and Lie-Super Algebra OSP(1,2) 215 Susumu Okubo

Quantum Tomography-Measurability of the Spin Density Matrix Revisited Bing-Lin Young

Measurability of the Spin Density Matrix

Roger G. Newton and Bing-Lin Young

\section{Particle Physics and Cosmology}

Sum-Rule for Large- $\mathrm{N}_{\mathrm{c}}$ QCD and Application to Heavy Quarkonia

Dean Lee and Howard Georgi

Leptonic Photon and Light Element Abundances

Lev B. Okun

Covariant Model of Relativistic Extended Particles Based on

the Oscillator Representation of the Poincaré Group

Young Suh Kim

Evidence for $\mathrm{JPC}=1^{-+}$Exotic Meson Production in the $\eta \pi$ System John P. Dowd

Decomposition Theory of Spin Connection, Topological Structure of

Gauss-Bonnet-Chern Topological Current and Morse Theory Yishi Duan and Sheng Li

Supersymmetry needs Left-Right Symmetry

Rabindra N. Mohapatra

Using Lifetime Dilation Effects to Test Transformations Between

Accelerated Frames

Jong-Ping Hsu, Leonardo Hsu and Yuan-Zhong Zhang

The QCD Coupling Constant From Tau Decays

Mark A. Samuel

Search for Quark Gluon Plasma in Relativistic Heavy Ion Collisions Chong-Shou Gao 
Modern Cosmology

Hong-Yee Chiu

\section{Symmetry}

Limiting Symmetry Principle, Universal Constants and

Generalized Lorentz Transformations for Non-inertial Frames

Jong-Ping Hsu and Leonardo Hsu

The Absolute Nature of the Velocity of Light

Y. C. Lee and W. Zhu

\section{Physics Education}

Augmenting Large Class Teaching Using the Classtalk System and the Web Charles Chiu

Appendix A. A Chronology of Ta-You Wu's Life and Career

George Y. C. Leung

Appendix B. Data of "Elementary Particles" (1998) for Comparison with Those on pp. 82-83 in "Innovation in Physics"

Appendix C. Captions and Credits of Photos 